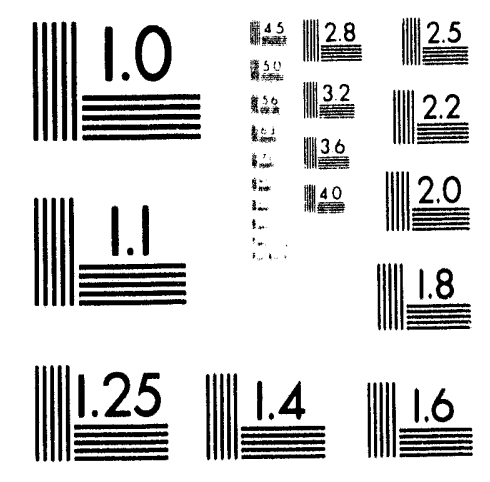




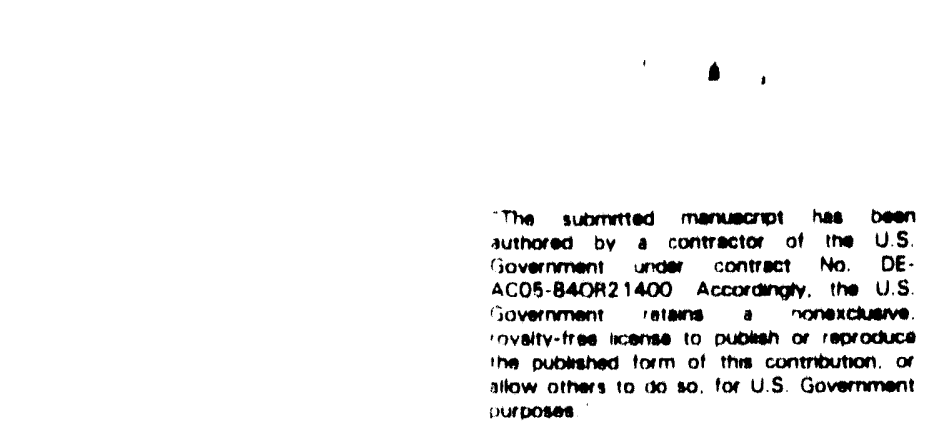

\title{
THE PRODUCTION OF ACCELERATED RADIOACTIVE ION BEAMS
}

\author{
D. K. Olsen \\ Oak Ridge National Laboratory,* P. O. Box 2008 \\ Oak Ridge, Tennessee 37831.6368 USA
}

\subsection{INTRODUCTION}

During the last few years, substantial work has been done and interest developed in the scientific opportunities available with accelerated radioactive ion beams (RIBs) for nuclear physics, astrophysics, and applied research. This interest has led to the construction, development, and proposed development of both first- and secondgeneration RIB facilities in Asia, North America, and Europe; international conferences on RIBs at Berkeley ${ }^{l}$ and Louvain-la-Neuve; ${ }^{2}$ and many workshops on specific aspects of RIB production and science. This paper provides a discussion of both the projectile fragmentation, PF, and isotope separator on-line, ISOL, approach to RIB production with particular emphasis on the latter approach, which employs a postaccelerator and is most suitable for nuclear structure physics. The existing, under construction, and proposed facilities worldwide are discussed. The paper draws heavily from the CERN ISOLDE work, ${ }^{3}$ the North American IsoSpin Laboratory (ISL) study, ${ }^{4}$ and the operating first-generation RIB facility at Louvain-la-Neuve, ${ }^{5}$ and the first-generation RIB project currently being constructed at ORNL. 6

The current interest in RIBs stems directly from the scientific opportunities these beams will provide for nuclear and astrophysics research and the fact that the acceleration of RIBs now is technically feasible. RIBs will greatly increase the number of nuclei which can be studied and, in particular, nuclei with extreme values of the neutron-proton ratio $N / Z$. Figure 1 shows the chart of the nuclides. All together, between the proton and neutron drip lines and the alpha-particle and fission limits of heavy nuclei, there are approximately 2700-particle-stable nuclei. Stable nuclei are shown as black squares in Fig. 1 and nuclei which would become accessible for the first time with a fully developed RIB facility such as the ISL are shown as shaded squares. Most of our nuclear structure information is from nuclei near beta stability which were produced in reactions of stable beams on stable targets; first with light-ion beams and then with heavy-ion beams. Much of the information on the neutron-rich side of beta

* Research sponsored by MUICh $840 R 21400$ with Martin Marietta Energy Systems, Inc. 


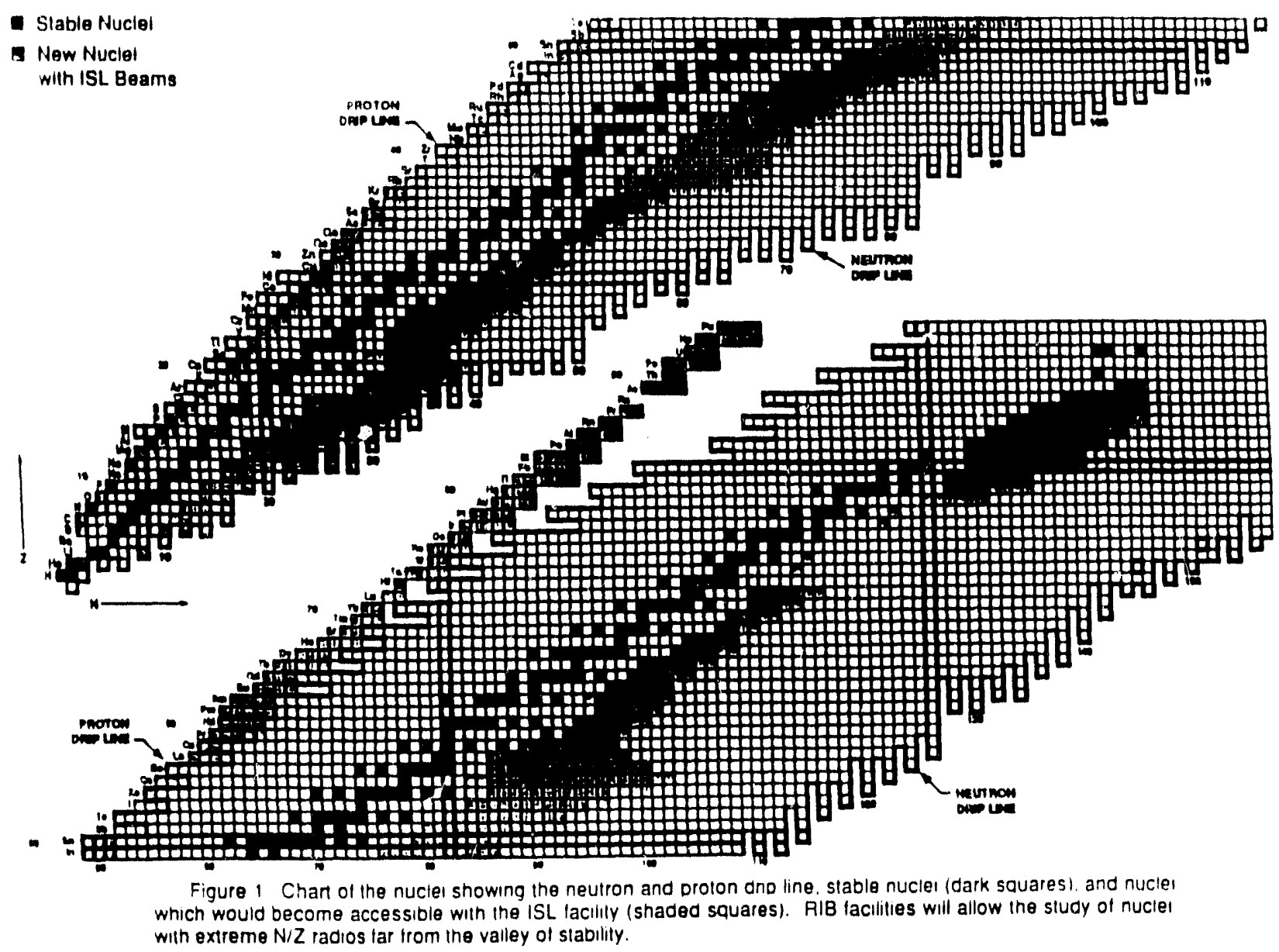

stability was obtained from the study of fission fragments; whereas, much of the information on the proton-rich side was obtained with stable heavv ion beams using fusion reactions. The acceleration of RIBs will allow access to new regions of protonand neutron-rich nuclei, giving exciting new research opportunities in both nuclear and astrophysics. In general, RIBs can be obtained by two very different methods: The projectile fragmentation method and the Isotope separator on line method. Generic parameters for experimental facilities, based on these two methods, are listed in Table 1.

\subsection{PROIECTILE FRAGMENTATION METHOD}

With the projectile fragmentation method, radioactive nuclei are produced in peripheral collisions between high-energy, heavy-ion projectiles and light target nuclei such as ${ }^{9} \mathrm{Be}$ or ${ }^{12} \mathrm{C}$. The incident beam is typically in the 50 to $2000 \mathrm{MeV} / \mathrm{A}$ range. The radioactive fragments are produced with velocities similar to that of the incoming projectile, in a forward-angle cone in the laboratory coordinate system, and are separated into an isobarically pure beam for experiments with a momentum loss achromate which is the critical component and is shown in Fig. 2. The first dipole magnet sorts the recoils by magnetic rigidity and the second dipole sorts the remaining recoils by energy loss, giving a relatively isotopically pure beam on target. The 
Table 1. Characteristics of methods for producing radioactive ion beams.

\begin{tabular}{|c|c|c|c|}
\hline \multirow[b]{2}{*}{$\begin{array}{l}\text { Primary } \\
\text { Accelerator }\end{array}$} & \multicolumn{2}{|c|}{ ISOL } & \multirow{2}{*}{$\begin{array}{l}\text { Fragmentation } \\
\text { Heavy-ion Cyclotron } \\
\text { or Synchrotron }\end{array}$} \\
\hline & $\begin{array}{l}\text { Small } \\
\text { Cyclotron }\end{array}$ & $\begin{array}{l}\text { Light-ion Linac } \\
\text { or Synchrotron }\end{array}$ & \\
\hline $\begin{array}{l}\text { Production } \\
\text { Reaction }\end{array}$ & $\begin{array}{l}\text { Fusion } \\
\text { Transfer }\end{array}$ & $\begin{array}{l}\text { Spallation } \\
\text { Fission }\end{array}$ & $\begin{array}{l}\text { Projectile } \\
\text { Fragmentation }\end{array}$ \\
\hline $\begin{array}{l}\text { Primary } \\
\text { Beam }\end{array}$ & $\begin{array}{l}\mathrm{H}, \mathrm{He} \\
50 \mathrm{MeV} / \mu\end{array}$ & $p_{i \mathrm{Gev} / \mu}$ & $\begin{array}{l}\mathrm{Au}, \mathrm{U} \\
1 \mathrm{GeV} / \mu\end{array}$ \\
\hline Target & $\begin{array}{l}\text { Thick } 1 \mathrm{~g} / \mathrm{cm}^{2} \\
\text { Any }\end{array}$ & $\begin{array}{l}\text { Thick } 100 \mathrm{~g} / \mathrm{cm}^{2} \\
\mathrm{U}, W\end{array}$ & $\begin{array}{l}\text { Thin } 1 \mathrm{~g} / \mathrm{cm}^{2} \\
\text { Be, C }\end{array}$ \\
\hline $\begin{array}{l}\text { Maximum } \\
\text { Cross section }\end{array}$ & $100 \mathrm{mb}$ & $10 \mathrm{mb}$ & $10 \mathrm{mb}$ \\
\hline $\begin{array}{l}\text { Production } \\
\text { Yield }\end{array}$ & $10^{-3}$ & $10^{-3}$ & $10^{-4}$ \\
\hline Product & Proton rich & $\begin{array}{l}\text { Proton and } \\
\text { Neutron rich }\end{array}$ & Neutron rich \\
\hline Separation & ISOL & ISOL & $\begin{array}{l}\text { Fragment } \\
\text { Separator }\end{array}$ \\
\hline $\begin{array}{l}\text { Source } \\
\text { Efficiency }\end{array}$ & $10^{-2}$ & $10^{-2}$ & $10^{-1}$ \\
\hline Delay time & Yes & Yes & No \\
\hline $\begin{array}{l}\text { Secondary } \\
\text { Accelerator }\end{array}$ & $\begin{array}{l}\text { Tandem, } \\
\text { Cyclotron, } \\
\text { Linac }\end{array}$ & $\begin{array}{l}\text { Tandem, } \\
\text { Cyclotron, } \\
\text { Linac }\end{array}$ & $\begin{array}{l}\text { Storage } \\
\text { Ring }\end{array}$ \\
\hline
\end{tabular}

efficiency of such systems depends strongly on the incident energy, since the angular spread and, hence, emittance of the RIBs decreases with increasing energy. Also, the target thickness can increase strongly with increasing energy. Hence, to increase the RIB intensity, the incident energy is increased and the resulting radioactive beam becomes too energetic for nuclear structure studies. Therefore, for many experiments, it is necessary to decelerate the RIBs using an energy-loss technique which results in poor emittance and energy spread.

The projectile fragmentation method has the advantage of being fast, so short halflife product nuclei can be used for experiments, and the method does not suffer from the target-beam-ion-source chemistry constraints of the ISOL method. Its primary 
disadvantage is that the RIBs are produced at high energies and the beam intensities, because of thinner targets and smaller primary beam intensities, are several orders of magnitude lower than those from the ISOL method. A more complete description of the projectile fragmentation method can be found in Ref. 7. Some of the larger facilities doing this work are GANIL, MSU, RIKEN, and GSI.

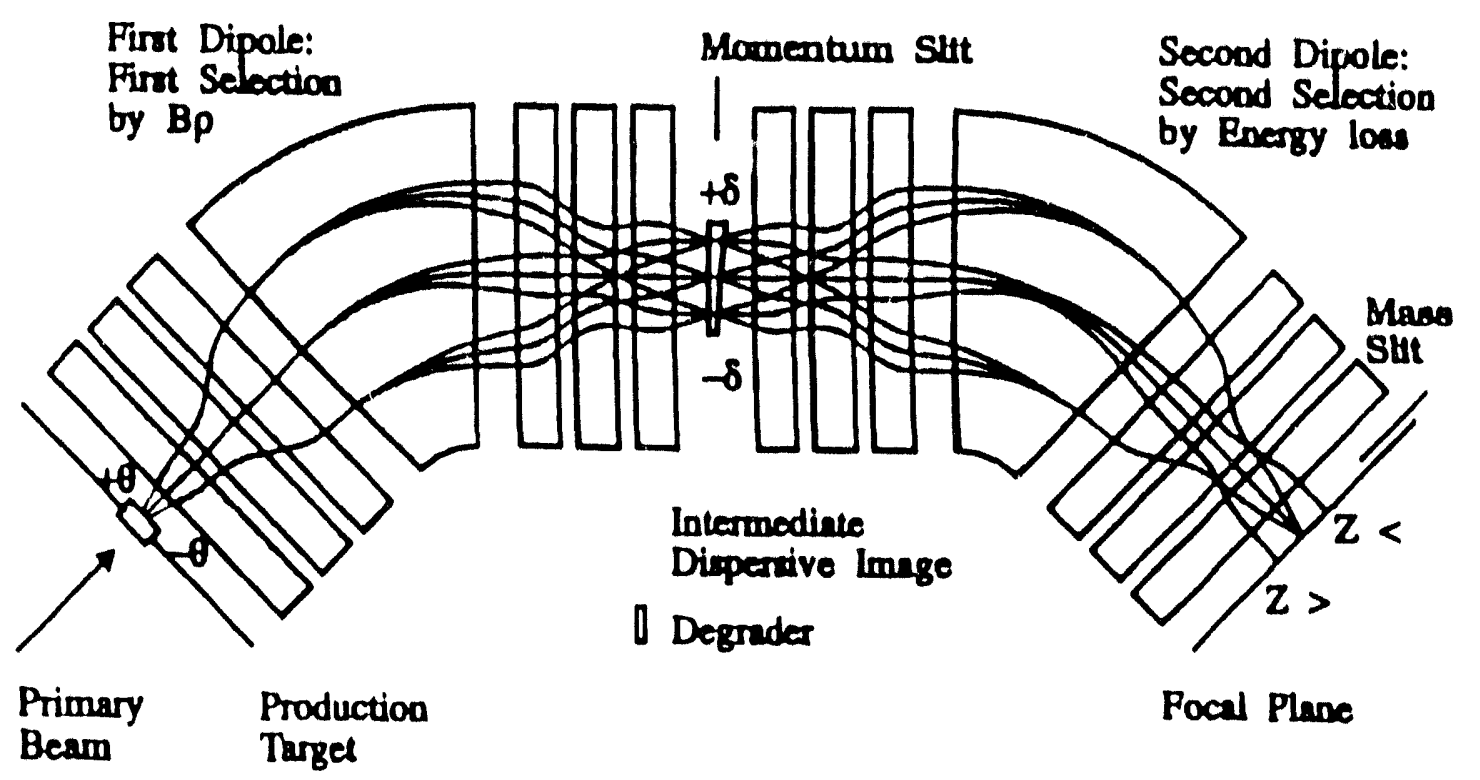

Figure 2. Schematic illustration of a momentum loss achromate for the projectile fragmentation technique.

\subsection{ISOL METHOD}

The ISOL method requires two accelerators, one to produce radioactive atoms at rest and a second to accelerate these radioactive atoms up to energies of interest. This method is somewhat equivalent to taking a low-energy RIB beam from an existing lowenergy ISOL ion source and accelerating this beam up to energies of interest for nuclear or astrophysics. The premier existing low-energy ISOL facility is ISOLDE ${ }^{3}$ at CERN. The crucial comporient is the target-ion source. Figure 3 shows the ORNL version of the CERN FEBIAD target-ion source. Radioactive atoms will be produced by bombarding thick stopping targets with high-intensity beams of light ions. The resulting radioactive atoms will diffuse and desorb from the target material, which will probably be a refractory ceramic, in powder form, and heated to $2000^{\circ} \mathrm{C}$. The radioactive atoms will effuse through a heated transport tube into the FEBIAD source where they are ionized and accelerated to about $50 \mathrm{KeV}$. The desired mass is separated with a magnetic mass separator. A very good mass separator with a mass resolution greater than $10^{-4}$ could separate isobars from a single mass chain providing isotopically pure beams on target. 


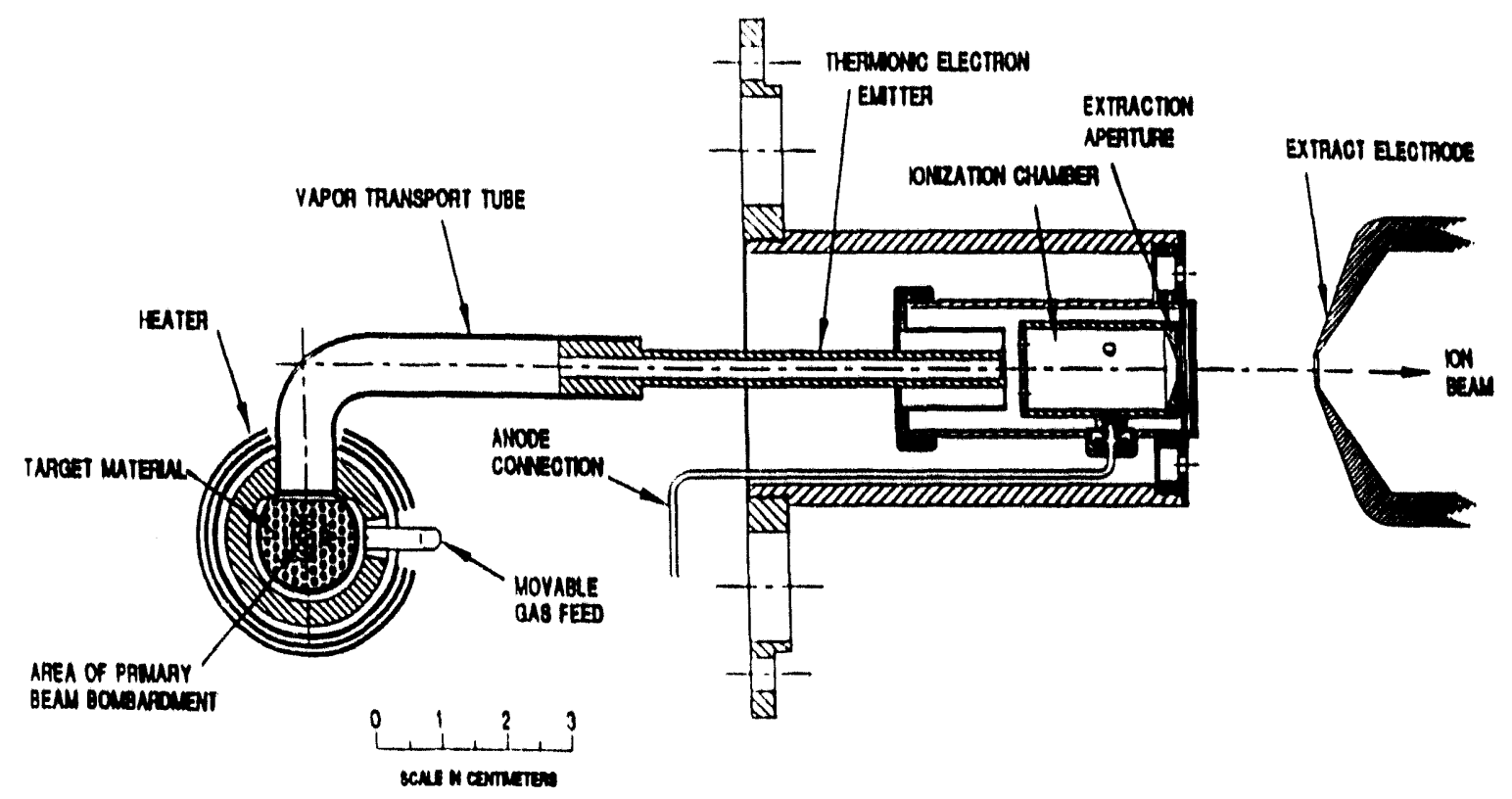

Figure 3. ORNL target-ion source based on the CERN ISOLDE FEBIAD design.

A very crucial disadvantage of the ISOL method, is that the diffusion and desorbtion of the radioactive atoms from the target material and the effusion and surface desorption in the transport tube and ion source are very dependent on the chemistry between the target material, the beam element, and construction materials. The ISOL method is much slower than the PF method, limiting RIBs to a half-life of about $100 \mathrm{~ms}$ or longer. However, the ISOL method is capable of producing very intense beams at energies of interest for nuclear spectroscopy and astrophysics. The choice of the light-ion primary accelerator depends on the method of producing the radioactive atoms. At least two mechanisms are usually considered: (1) The production of predominantly proton-rich radioactive atoms using low-energy, light-ioninduced fusion reactions. This mechanism is presently being pursued with existing low-energy accelerators at Louvain-la-Neuve and Oak Ridge. These facilities are sometimes referred to as first-generation facilities since only a limited number of RIBs can be produced. (2) The production of both proton- and neutron-rich radioactive atoms from spallation, fission, and fragmentation using high-energy, light-ion beams as is done at ISOLDE. This mechanism probably will provide the largest variety of radioactive nuclei and requires primary accelerators similar to those used for spallation neutron and meson production. Such facilities are presently under study and can, in principle, produce a wide variety of RIBs.

\subsection{RIB FACILITIES AND PROJECTS BASED ON THE ISOL METHOD}

Table 2 lists most of the ISOL RIB facilities, which are either operational, funded, proposed, or discussed. Presently, the only operating facility is at Louvain-la-Neuve which has accelerated both ${ }^{13} \mathrm{~N}$ and ${ }^{19} \mathrm{Ne}$ beams for astrophysics research with intensities of $4 \times 10^{8} \mathrm{pps}$ and $2 \times 10^{9} \mathrm{pps}$, respectively. The driver, CYCLONE 30, is a compact, medical $\mathrm{H}^{-}$cyclotron originally designed to produce an intense $30-\mathrm{MeV}$ 
proton beam which is transported to a target located in a 3-m-thick concrete shielding wall. For ${ }^{13} \mathrm{~N}$ beams, a $50 \%$-enriched, $13 \mathrm{C}$, thick graphite-powder target is embedded into a graphite rod in good thermal contact with a water-cooled copper cylinder. The resulting ${ }^{13} \mathrm{~N}$ activity from $(p, n)$ reactions is extracted as $13 \mathrm{~N}-14 \mathrm{~N}$ gas molecules. The $170-\mu \mathrm{A}$ proton beam heats the target to about $2300 \mathrm{~K}$. The $13 \mathrm{~N}-1+\mathrm{N}$ gas is transported to a single-stage ECR ion source which has a $8 \%$ ionization efficiency. The resulting $13 \mathrm{~N}^{1+}$ ions are mass analyzed, transported to a second cyclotron, CYCLONE, axially injected and accelerated with a $6 \%$ efficiency. A very important problem has been the separation of evaporated ${ }^{13} \mathrm{C}$ from the ${ }^{13} \mathrm{~N}$ beam and this has been achieved by the high intrinsic resolving power of the CYCLONE magnetic field. The work at Louvain-laNeuve will be extended with the ARENAS project funded to build a new highefficiency $k=70$ cyclotron postaccelerator for astrophysical energies. This will allow the $k=130$ CYCLONE to also be used as a driver.

It was realized early by Hansen ${ }^{9}$ in 1977 that many of the intense low-energy RIBs developed at ISOLDE, some of them reaching $10^{12}$ pps, could be accelerated to energies of interest for nuclear and astrophysics. This has led to an ISOLDE RIB accelerator project PRIMA. ${ }^{10}$ The proposed RIB linear accelerator would, in its first stage, produce beams with masses below 27 and energies below $1.4 \mathrm{MeV} / \mathrm{A}$ for experiments in nuclear astrophysics, nuclear reactions and spectroscopy, for polarization studies, and for solid state applications. CERN also is collaborating with the Rutherford-Appleton Laboratory on a high-power target-ion source test. The ISIS spallation neutron source, driven by a $200-\mu \mathrm{A}, 800-\mathrm{MeV}$ proton beam at Rutherford is an ideal driver for a RIB facility. This fact has led to a very serious discussion of developing a RIB facility at ISIS using part of this intense proton beam. Both linacs and synchrotrons have been discussed as postaccelerators. The UK Science and Engineering Research Council has funded a test bed facility at Rutherford to determine whether very high proton intensities can, in fact, be utilized for the production of RIBs. This equipment is funded and under development for a 160-kW target-ion source test in 1994-95 as a proof of principle for a second-generation source.

As an extension to the already existing high-energy projectile-fragmentation RIB capabilities, GANIL physicists will produce RIBs by the ISOL method.12 As listed in Table 2, radioactive atoms will be produced with the $95 \mathrm{MeV} / \mathrm{A}$ beams of heavy ions from existing $k=380$ cyclotrons and RIBs would be accelerated in a funded $k=265$ compact cyclotron. There is some debate on the efficiency of light-heavy ions for RIB production compared with 0.5 to $1.0 \mathrm{GeV}$ protons. The cross section for RIB production with $95-\mathrm{MeV} / \mathrm{A}$ light-heavy ions is larger than for energetic protons; however, this increase in cross section may be more than compensated by a decrease in effective target thickness. Also, target power density may be a problem at the planned intensities. In any case, a compact, high-efficiency, high-charge-state ECR source has been developed 
and used as a proof of principle by producing $\mathrm{Ne}$ RIBs from low-power ${ }^{12} \mathrm{C}$ bombardment of a $\mathrm{MgO}$ target.

\begin{tabular}{|c|c|c|c|c|c|c|c|}
\hline EACULITY & $\begin{array}{l}\text { DRIVER } \\
\text { ACCELERATOR }\end{array}$ & $\begin{array}{l}\text { RIB } \\
\text { ACCELEBATOB }\end{array}$ & $\begin{array}{l}\text { MASS } \\
\text { GANGE }\end{array}$ & $\begin{array}{l}\text { ENERGY } \\
\text { MEVIA }\end{array}$ & $\begin{array}{l}\text { INTENSITY } \\
\text { PPS }\end{array}$ & STATUS & BEE \\
\hline $\begin{array}{l}\text { RIB Project } \\
\text { Louvain-la.Neuve }\end{array}$ & $k=30 \mathrm{H}-$ cyclotron & $k=110$ cyclotron & $\leq 20$ & $\leq 1.5$ & $\begin{array}{l}13 \mathrm{~N} 3 \times 10^{8} \\
19 \mathrm{Ne} 2 \times 10^{9}\end{array}$ & Operational & 5 \\
\hline $\begin{array}{l}\text { ARENAS Prolect } \\
\text { Louvain-la-Neuve }\end{array}$ & $\begin{array}{l}k=30 \mathrm{H} \text {-cyciotron } \\
k=110 \text { cyclotron } \\
80 . \mathrm{MeV} \text { protons }\end{array}$ & $\begin{array}{l}\text { (new nign-efficiency } \\
k=70 \text { cyciotron) }\end{array}$ & $\leq 30$ & $\leq 1.5$ & $\$ 109$ & Funded & 5 \\
\hline $\begin{array}{l}\text { ORNL RIB Pro!ect } \\
\text { Oak Ridge }\end{array}$ & $\begin{array}{l}k=100 \text { cyclotron } \\
65 \cdot \mathrm{MeV} \text { protons }\end{array}$ & 25-MV landem & $\leq 80$ & $\leq 5.0$ & $\leq 1011$ & $\begin{array}{l}\text { Under } \\
\text { Construction }\end{array}$ & 6 \\
\hline Catania & $x=800 \mathrm{SC}$ cyclotron & 15. MV landem & & & $\leq 10^{9}$ & Discussed & 8 \\
\hline $\begin{array}{l}\text { CERN PRIMAA } \\
\text { ISOLDE }\end{array}$ & $\begin{array}{l}1.0 . \mathrm{GeV} D \\
\text { syncnrotron }\end{array}$ & (linac) & $\leq 27$ & $\leq 1.4$ & $\$ 10^{9}$ & $\begin{array}{l}\text { Discussed } \\
\text { operating ISOL }\end{array}$ & 10 \\
\hline $\begin{array}{l}\text { ISIS } \\
\text { Ruthertoro }\end{array}$ & $800-\mathrm{MeV} p$ & (tinac or synchrotron) & $<240$ & 6.5 & $\leq 1012$ & $\begin{array}{l}\text { Discussed } \\
\text { larget testing }\end{array}$ & 11 \\
\hline GANIL & $\begin{array}{l}k=380 \mathrm{HI} \text { cyciotron } \\
1.1 . \mathrm{GeV} 12 \mathrm{C}\end{array}$ & $k=265$ cyclotron & $\leq 220$ & $25 \cdot 50$ & $<10^{9}$ & $\begin{array}{l}\text { Tested with } \\
\text { ECR source }\end{array}$ & 12 \\
\hline $\begin{array}{l}\text { TAIUMF. ISAC } \\
\text { TISOL }\end{array}$ & $k=500 \mathrm{H}^{-}$cyclotron & (linac) & $\leq 60$ & $\leq 1.6$ & $\leq 10^{12}$ & $\begin{array}{l}\text { Proposed } \\
\text { Operaling ISOL }\end{array}$ & 13 \\
\hline INS Tokyo & $k=65$ cyclotron & (linac) & $<45$ & 1.0 & 109 & $\begin{array}{l}\text { Under } \\
\text { Construction }\end{array}$ & 14 \\
\hline JHP. KEK & (1.0.GeVp linac) & (linac) & $<60$ & 6.5 & $<10^{12}$ & Discussed & 14 \\
\hline ISL BMF & $\begin{array}{l}(0.5 \cdot 1.0 \mathrm{GoV} \\
\text { crotons) }\end{array}$ & $(\operatorname{linac})$ & $<240$ & 10.0 & $<1011$ & Discussed & 4 \\
\hline
\end{tabular}

A collaboration centered around the TRIUMF high-intensity, $500-\mathrm{MeV} \mathrm{H}^{-}$ cyclotron has constructed and tested an on-line mass separator, TISOL, and has developed a proposal for an accelerated radioactive beam facility, ISAC. ${ }^{13}$ As part of this development, a single-stage ECR source has been designed, installed on the mass separator, and tested with the TRIUMF beam. ${ }^{1}$ An experimental program with this facility has been started. The ISAC proposal now consists of an RFQ to capture, bunch, and pre-accelerate the very low energy, singly charged ions from the isotope separator to $60 \mathrm{keV} / \mathrm{A}$, followed by a stripper to increase the mass to charge ratio before further acceleration in a SC linac. The overall length of the linac is $16.3 \mathrm{~m}$ with an output energy of $1.6 \mathrm{MeV} / \mathrm{A}$ for masses $\mathrm{A} \leq 60$.

Also listed in Table 2 is the RIB facility proposed as a part of the Japanese Hadron Project put forth by the INS in Tokyo. The RIB facility will be driven by a future highintensity 1-GeV proton linac and the RIB accelerator will be the usual RFQ-SC linac scheme. As a development project, the INS group is building a system to accelerate RIBs of astrophysical interest by means of ISOLDE-type target-ion sources and a new high-resolution mass separator on-line to the existing $40-\mathrm{MeV}$ proton beam from the 
INS cyclotron. A prototype Split-Coaxial-RFQ postaccelerator linac combination is being built to accelerate RiBs to $1.0 \mathrm{MeV} / \mathrm{A}$.

Both the physics case for research and an ideal, but achievable, accelerator complex has been developed in some detail by a group of physicists for a major North American RIB facility, the ISL. ${ }^{4}$ This facility would accelerate RIBs with all masses to energies of $10 \mathrm{MeV} / \mathrm{A}$ with intensities up to $10^{11}$ pps. A $100-\mu \mathrm{A}, 0.5$ to $1.0-\mathrm{GeV}$ proton beam from an existing or new driver would produce radioactive atoms in an ISOL target-ion source assembly similar to that of ISOLDE. A single isotope would be selected with a mass separator with a mass resolution in the order of 30,000 and then would be accelerated up to $10 \mathrm{MeV} / \mathrm{A}$. This concept is meant to be the most ambitious, technically achievable project with more or less existing technology. Major uncertainties with such a facility are the approximately $75 \mathrm{~kW}$ of beam power that must be dissipated in the target-ion source, the associated radiation, and the very low velocity linac required for initial acceleration of singly-charged heavy RIBs.

\subsection{ORNL RIB PROJECT}

In August 1992, the HHIRF shut down as a national users facility for stable heavy ion beams and became a development project to reconfigure the two accelerators to provide a quick and economic first-generation, proton-rich, RIB facility for North America. In the past, the Oak Ridge Isochronous Cyclotron (ORIC) has served as an energy booster for stable heavy ions from the 25-MV tandem accelerator. To produce RIBs, this process will simply be reversed: the tandem accelerator would be injected with radioactive heavy ions produced by light ions from ORIC. In this case, the two accelerators will be coupled by a new RIB injector consisting of an ISOLDE-type thicktarget, ion-source assembly, mass separator, and charge exchange canal, all mounted on a 300-kV high-voltage platform in an existing shielded room.

\subsection{Existing Components}

A central feature of the project is that most of the main components already exist. The new hardware required for this RIB reconfiguration is shown in Fig. 4. The existing components include the UNISOR on-line isotope separator which has been operating since 1971, is managed and used by a consortium of university physicists, and provides extensive in-house experience. UNISOR, with its FEBIAD ion source, has allowed the immediate investigation and development of the target and ion-source materials, geometry, chemistry, and procedures required to produce RIBs for subsequent acceleration. In particular, experiments have started in which elements for future RIBs are implanted in thick target materials of interest, allowing the chemistry and physics of the subsequent thermal diffusion, desorption, and ionization to be studied independently of producing RIBs. ${ }^{15}$ 


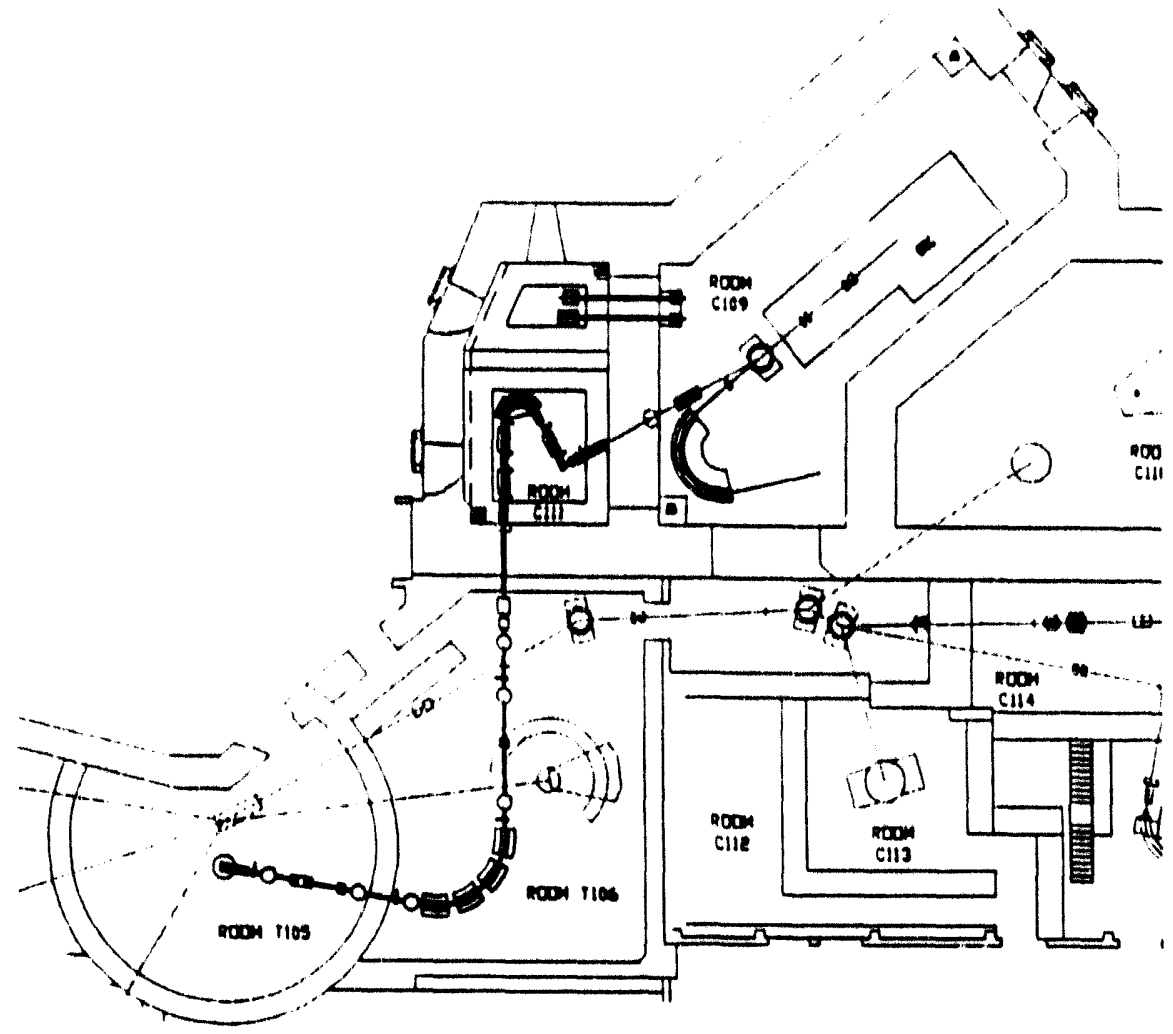

Figure 4. Additional hardware required to recontigure the ORNL accelerator system to produce RIBs.

The existing tandem presently operates at $25 \mathrm{MV}$, the highest electrostatic accelerator voltage in the world. The charge state fractions and transmission efficiencies through the tandem have been extensively measured. With gas stripping, beams of mass 52 can be accelerated above $5 \mathrm{MeV} / \mathrm{A}$ with a total efficiency of over $20 \%$. With foil stripping, beams of mass 80 can be accelerated above $5 \mathrm{MeV} / \mathrm{A}$ with a total efficiency of over $8 \%$. Beams of lower masses can be accelerated to higher energies with total efficiencies approaching 50\%. The tandem accelerator has some very important advantages for RIBs and no major modifications would be required for service with RIBs. Since it is inherently a dc machine, no bunching is required for the injected beam, thus maximizing the beam available from the RIB target ion source. In addition, the tandem's simplicity, reliability, and excellent beam quality, are unmatched.

The existing $k=100$ ORIC was designed for the acceleration of both light and heavy ions and was used extensively for intense light-ion beains in the first years after its completion in the early 1960s. ORIC was designed to accelerate $1 \mathrm{~mA}$ of $75-\mathrm{MeV}$ protons, making ORIC an ideal driver for the intense light-ion primary beams needed to produce RIBs. Over $2 \mathrm{~kW}$ of extracted beam power are expected for $\mathrm{H}$ and $\mathrm{He}$ beams. For first operation, $0.5 \mathrm{~kW}$ of extracted beam power seems readily achievable. In addition to the two accelerators, shielded space is another important existing component. The shielding for the original ORIC vault and target rooms was also designed for $75-\mathrm{MeV}, 1-\mathrm{mA}$ proton beams. In the present plan, room $\mathrm{C} 111$, shown in 
Fig. 5, will house the new RIB injector. No new civil construction is required for the ORNL RIB project.

\subsection{Additional Equipment}

The additional equipment consists mostly of a RIB injector, including a reconfigured light-inn transport line from ORIC and a new RIB transport line to the tandem. The HV platform system for the RIB injector is rather complicated for two reasons: First, the tandem design was optimized for a high injection voltage and this requires the injection voltage to be specified at $300 \mathrm{kV}$. Secondly, the neutron fluence from the RIB target has been estimated to be 0.07 fast neutrons from each $60-\mathrm{MeV}$ proton stopping in a mass 70-region target, which corresponds to a neutron fluence of about $1 \times 10^{15} \mathrm{n} / \mathrm{cm}^{2}$ one meter from the target for a $33-\mu \mathrm{A}$ beam for 2000 hours. Nearly all unshielded semiconductor devices near the target-ion source could be destroyed in one year of operation at this radiation level. The HV platform system which solves these two problems is shown in Fig. 6. Two platforms with a common power supply will be used. One platform, the source platform, will support most of the mechanical equipment, including the target-ion source and beam transport. The second platform, the instrumentation platform, will support most of the electrical apparatus,

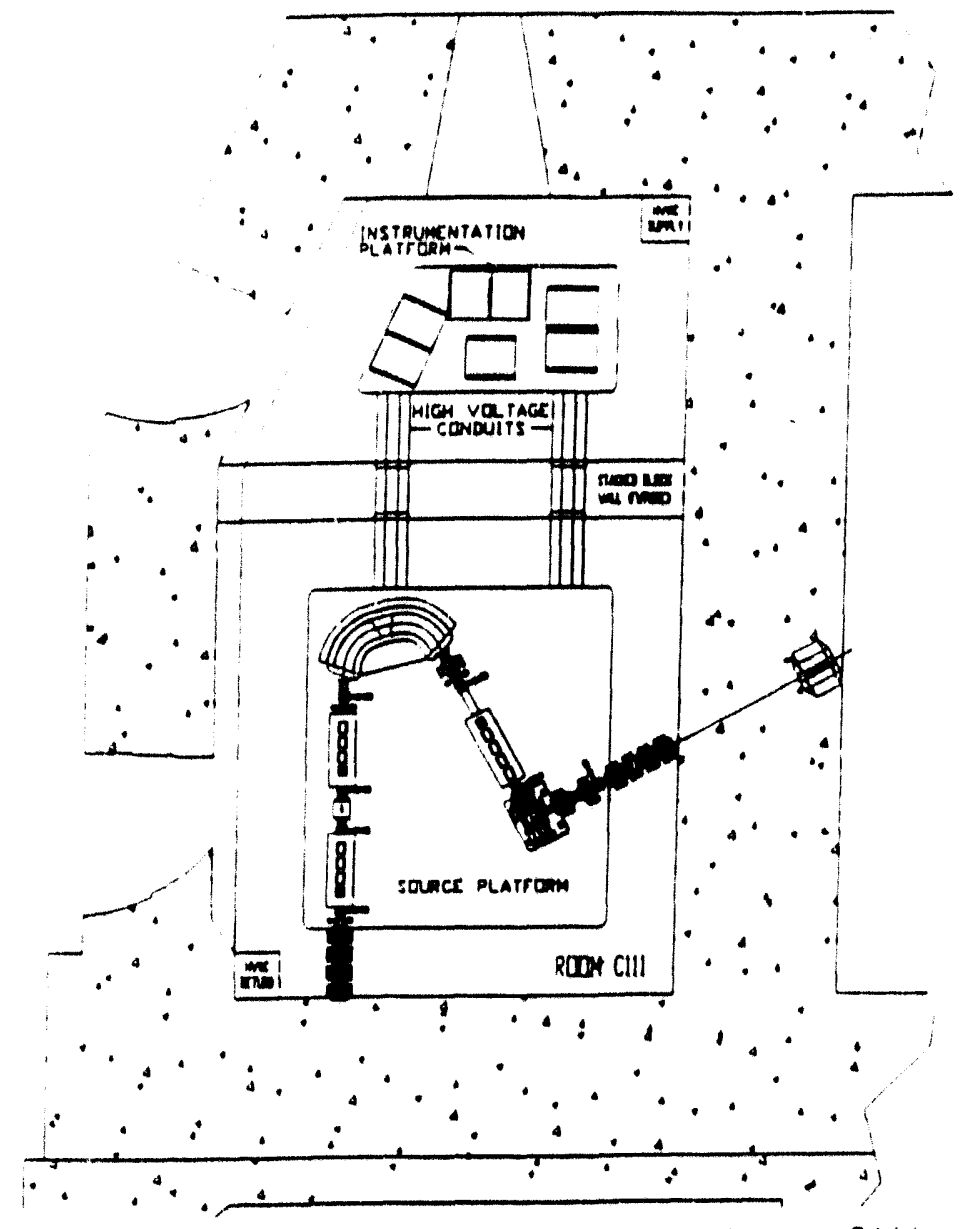

Figure 5. Floor plan of the new ORNL RIB injector in room C111. 
including all power supplies. The two platforms will be separated by a concrete shielding wall, but connected electrically by two HV conduits to carry cables at the platform potential and ion source potential. The ORIC light-ion beam will enter the source platform through one $300-\mathrm{kV}$ acceleration tube and RIBs will exit through a second $300-k V$ tube. The target-ion source assembly will produce positive-ion beams with many different elements, molecules, isotopes, and charge states. Some element selection will occur because of physics and chemistry factors; however, in general, this beam needs to be filtered to produce an isotopically pure beam on target with a twostage magnetic-mass-separator system. The first-stage mass separator will be a $155^{\circ}$ symmetric split-pole dipole magnet, giving an expected mass resolution greater than $1 / 1000$ and will select a single isobaric mass chain. The beam will be refocused into a round beam for transport through a charge-exchange cell. The negative-ion output beam will be refocused by another lens into the entrance of the $300-\mathrm{kV}$ tube.

\section{HHIRF EOREXOTIC BEAMS}

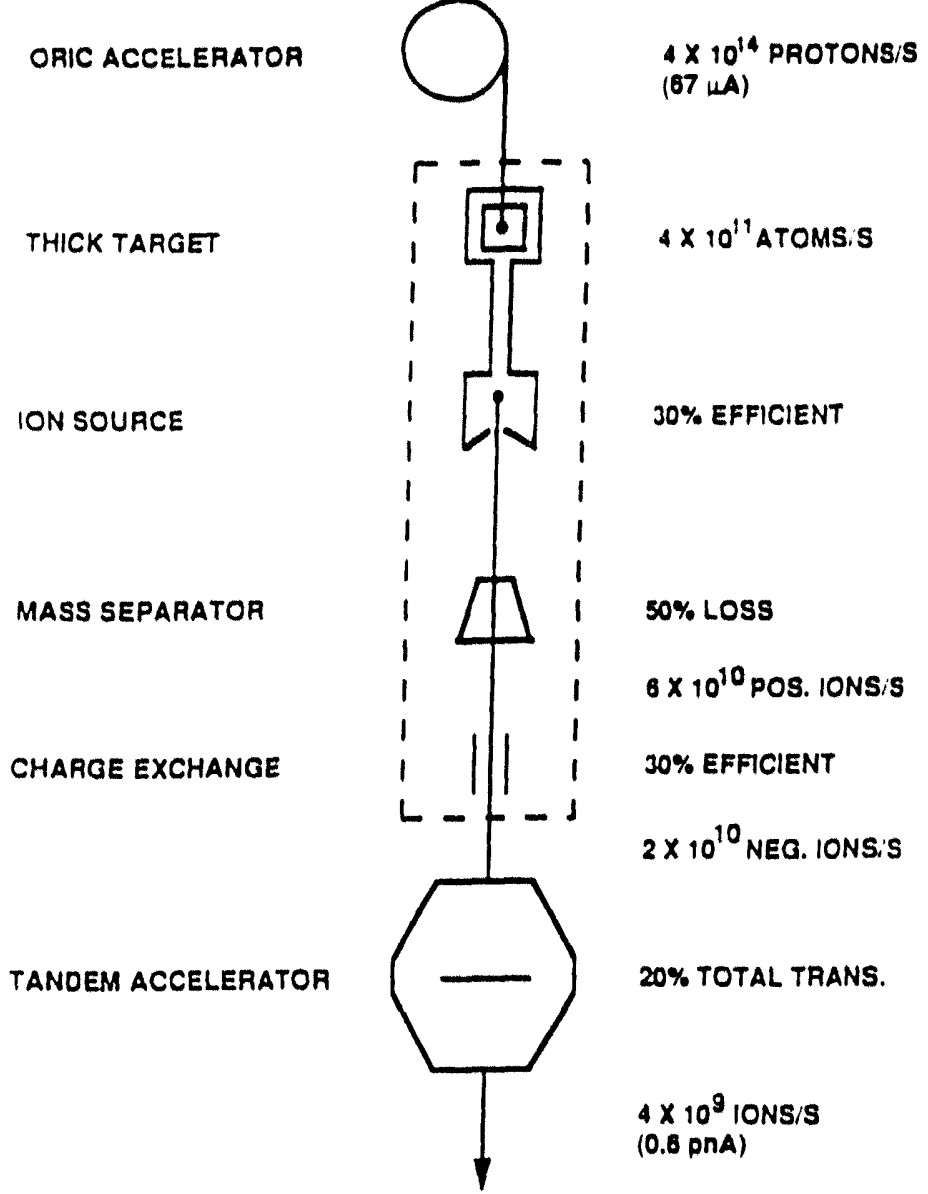

Figure b. Summary of the ORNL concept and average efficiencies for a "very good case" NIB produced with $67 \mu \mathrm{A}$ of $30-\mathrm{MeV}$ protons. About $10^{-5}$ of the primary beam or $0.6 \mathrm{pnA}$ i) RIBs would be produced as beam on target. 
The second stage of the mass separator will be part of the negative-ion injection line from the high-voltage source platform to the tandem accelerator as shown in Fig. 5. The line is about $40 \mathrm{~m}$ long with a $110^{\circ}$ horizontal bend and a $90^{\circ}$ vertical bend directly below the tandem to inject the RIB through the de-energized, existing injector magnet. The $110^{\circ}$ horizontal bend will be divided into four dipoles with radius of curvature of $2.30 \mathrm{~m}$, giving a mass resolving power greater than one part in 10,000.

\subsection{Expected Energy and Intensity}

The process for producing RIBs with the HHIRF accelerator system is summarized quantitatively for a generic "very good case" in Fig. 6. The process starts with ORIC, for which it has been assumed that eventually $2.0 \mathrm{~kW}$ of $\mathrm{H}$ or He beam will be extracted, giving $67 \mu \mathrm{A}$ or $4 \times 10^{14}$ protons per second. These protons will be accelerated onto the HV platform and stopped in a thick target. For a good case, with an isotopically pure elemental target, about one radioactive atom can be produced for each 1000 incident protons, giving $4 \times 10^{11}$ radioactive atoms per second. This production rate is very optimistic and assumes no decay, target release, or surface sticking losses. On a verage, these radioactive atoms can be positively ionized with a $30 \%$ efficiency, mass analyzed with a $50 \%$ efficiency, and charge exchanged with a 30\% efficiency, giving $2 \times 10^{10}$ of negative radioactive ions per second out of the RIB injector. Radioactive ions below mass 80 can be accelerated in the tandem accelerator on average with a $20 \%$ total efficiency, giving $4 \times 10^{9}$ ions per second as beam-on-target for a very good case under ideal conditions. To summarize, the loss in intensity between the ORIC beam and the RIB beam will be at least a factor of 100,000; a factor of 1,000 to make radioactive atoms, and then, on average, another factor of 100 to deliver these radioactive atoms as beam on target.

The maximum possible energies and intensities for RIBs from the tandem accelerator for some of the most interesting and intense specific beams are listed in Table 3 for an initial ORIC beam power of $0.5 \mathrm{~kW}$. With single stripping, masses up to about 80 can be accelerated to energies above $5 \mathrm{MeV} /$ nucleon. The maximum currents for these beams are much more difficult to estimate. Examination of this table shows that many of the RIBs listed have potential intensities greater than $0.1 \mathrm{pnA}$, the intensity that can be used for experiments with $4 \pi$ detector systems. Fluorine and chlorine, which combine favorable production reactions, surface negative ionization, and acceleration efficiencies, are expected to be the most intense RIBs. It should be emphasized that Table 3 does not contain decay loss or release rate factors. 
Table 3. Estimated Maximum Beam Intensities and Energies from the ORNL Radioactive Ion Beam Facility."

\begin{tabular}{|c|c|c|c|c|c|}
\hline Isotode & $\begin{array}{c}\text { Beam } \\
\text { Intensity } \\
\text { (lons/s) }\end{array}$ & $\begin{array}{l}\text { Maxımum } \\
\text { Beam Energy } \\
\text { (MeV/Amu) }\end{array}$ & Isotope & $\begin{array}{c}\text { Beam } \\
\text { Intensity } \\
\text { (lons/s) }\end{array}$ & $\begin{array}{l}\text { Maximum } \\
\text { Beam Energy } \\
\text { (MeV/Amu) }\end{array}$ \\
\hline${ }^{10} \mathrm{C}$ & $4.3 \times 10^{7}$ & 13.0 & $38 \mathrm{~K}$ & $3.3 \times 10^{7}$ & 6.8 \\
\hline${ }^{11} \mathrm{C}$ & $5.0 \times 10^{7}$ & 13.0 & ${ }^{58} \mathrm{Cu}$ & $1.0 \times 10^{9}$ & 6.3 \\
\hline 140 & $1.4 \times 10^{8}$ & 13.0 & $63 \mathrm{Ga}$ & $1.8 \times 10^{5}$ & 6.1 \\
\hline 150 & $3.3 \times 10^{8}$ & 13.0 & $64 \mathrm{Ge}$ & $1.8 \times 10^{8}$ & 6.0 \\
\hline $17 \mathrm{~F}$ & $1.1 \times 10^{10}$ & 12.7 & $68 \mathrm{As}$ & $1.1 \times 10^{9}$ & 5.9 \\
\hline $18 \mathrm{~F}$ & $5.8 \times 10^{9}$ & 12.3 & 69 As & $1.3 \times 10^{9}$ & 5.9 \\
\hline $21 \mathrm{Na}$ & $4.3 \times 10^{7}$ & 11.2 & $70 \mathrm{Se}$ & $1.9 \times 10^{8}$ & 5.8 \\
\hline$=2 \mathrm{Na}$ & $4.3 \times 10^{7}$ & 10.7 & $71 \mathrm{Se}$ & $9.3 \times 10^{7}$ & 5.7 \\
\hline $26 \mathrm{Si}$ & $1.2 \times 10^{9}$ & 8.8 & $74 \mathrm{Br}$ & $3.3 \times 10^{7}$ & 5.5 \\
\hline $27 \mathrm{Si}$ & $1.0 \times 10^{9}$ & 8.8 & $76 \mathrm{Br}$ & $1.7 \times 10^{7}$ & 5.3 \\
\hline $33 \mathrm{Cl}$ & $2.5 \times 10^{10}$ & 7.8 & $77 R b$ & $1.4 \times 10^{5}$ & 5.3 \\
\hline${ }^{34} \mathrm{Cl}$ & $2.2 \times 10^{10}$ & 7.5 & $78 R b$ & $1.2 \times 10^{5}$ & 5.2 \\
\hline $37 K$ & $6.5 \times 10^{6}$ & 7.0 & & & \\
\hline
\end{tabular}

These estimates are for $0.5 \mathrm{~kW}$ of ORIC beam power, isotopically pure targets, and do not include any decay, target release, or surface sticking losses.

\subsection{Work in Progress}

At present, a substantial amount of work has been completed and is in progress at ORNL to develop a RIB capability. Internal ion source operation of the ORIC accelerator is being restored and central region calculations are being done to optimize the ion source geometry in order to minimize beam losses and maximize extracted iight-ion beam. UNISOR implantation studies have been initiated. Two target-ion source assemblies have been designed and fabricated. Room C111 has been remodeled to house the new RIB injector which will be delivered October 4, 1993. Much of the equipment for the RIB injector has been ordered, designed, or purchased. The beam line from ORIC to the RIB injector is nearly complete and a conceptual design exists for the second-stage mass separator and new RIB injection line. The new RIB injector should be completed in the first half of 1994, allowing the production and optimization of 300-kV RIBs produced with ORIC. The first RIBs from the tandem accelerator should occur in 1995.

\subsection{CONCLUSIONS}

It appears that accelerator-based nuclear physics which, only a few decades ago, moved, in part, from light-ion to heavy-ion beams, is now starting to move, in part, from stable-heavy-ion to radioactive-heavy-ion beams. The exciting physics opportunities presented by accelerated RIBs will lead to the development of several such facilities world-wide. Initially, these will be first-generation facilities such as that 
now operating at Louvain-la-Neuve and under construction at ORNL. Eventually, at least one very large second-generation RIB facility cauable $n^{f}$ accelerating all masses to energies above the Coulomb barrier should be developed.

\section{REFERENCES}

1. Proc. First Int. Conf. on Radioactive Nuclear Beams, Berkeley, CA, October 1989, eds. W. D. Myers, J. M. Nitschke, and E. B. Norman (World Scientific, Singapore, 1990).

2. Proc. Second Int. Conf. on Radioactive Nuclear Beams, Louvain-la-Neuve, Belgium, August 1991, ed. by Th. Delbar (Adam Hilger, Bristol, 1992).

3. H. L. Ravn and B. W. Allardyce, Treatise on Heary lon Science, ed. D. A. Bromley, Vol. VIII, Nuclei Far From Stability (Plenum Press, New York, 1989), p. 363.

4. R. F. Casten et al., The IsoSpin Laboratory (ISL), Research Opportunities with Radioactive Nuclear Beams, LALP91-51, (LANL, Los Alamos, 1991).

5. G. Berger et al., Proc. of the 1991 IEEE Particle Accelerator Conference, p. 2610, 91CH3038, (San Francisco, May 1991).

6. D. K. Olsen et al., Proc. Second Int. Conf. on Radioactive Nuclear Beams, Louvainla-Neuve, Belgium, August 1991, ed. by Th. Delbar (Adam Hilger, Bristol, 1992), p. 131.

7. B. M. Sherrill, Proc. Second Int. Conf. on Radioactive Nuclear Beams, Louvain-laNeuve, Belgium, August 1991, ed. by Th. Delbar (Adam Hilger, Bristol, 1992) p. 3.

8. E. Migneco, Int. Workshop on the Physics Techniques of Secondary Nuclear Beams, Dourdan, France, March 23-25, 1992.

9. P. G. Hansen, Proc. CERN Workshop on Intermediate Energy Physics for Unstable Nuclei and Radioactive Ion Beams, CERN PS-CDI/77-43 (1977).

10. H. Haas, et al, Proc. First Int. Conf. on Radioactive Nuclear Beams, Berkeley, CA, October 1989, eds. W. D. Myers, J. M. Nitschke, and E. B. Norman (World Scientific, Singapore, 1990) p. 59.

11. J. R. J. Bennett et al., Proc. of Workshop on the Production and Use of RIBs at the ISL, Oak Ridge, October 1992, ed. J. D. Garrett, p. 289.

12. A. Chabert, et al., Proc. Second Int. Conf. on Radioactive Nuclear Beams, Louvainla-Neuve, Belgium, August 1991, ed. by Th. Delbar (Adam Hilger, Bristol, 1992) p. 115.

13. L. Buchmann, Proc. Second Int. Conf. on Radioactive Nuclear Beams, Louvain-laNeuve, Belgium, August 1991, ed. by Th. Delbar (Adam Hilger, Bristol, 1992) p. 109.

14. T. Nomura, Proc. First Int. Conf. on Radioactive Nuclear Beams, Berkeley, CA, October 1989, eds. W. D. Myers, J. M. Nitschke, and E. B. Norman (World Scientific, Singapore, 1990) p. 13.

15. G. D. Alton $\mathrm{A}$ : al., Proc. Second Int. Conf. on Radioactive Nuclear Beams, Louvainla-iNeuve, Belgium, August 1991, ed. by Th. Delbar (Adam Hilger, Bristol, 1992) p. 95. 

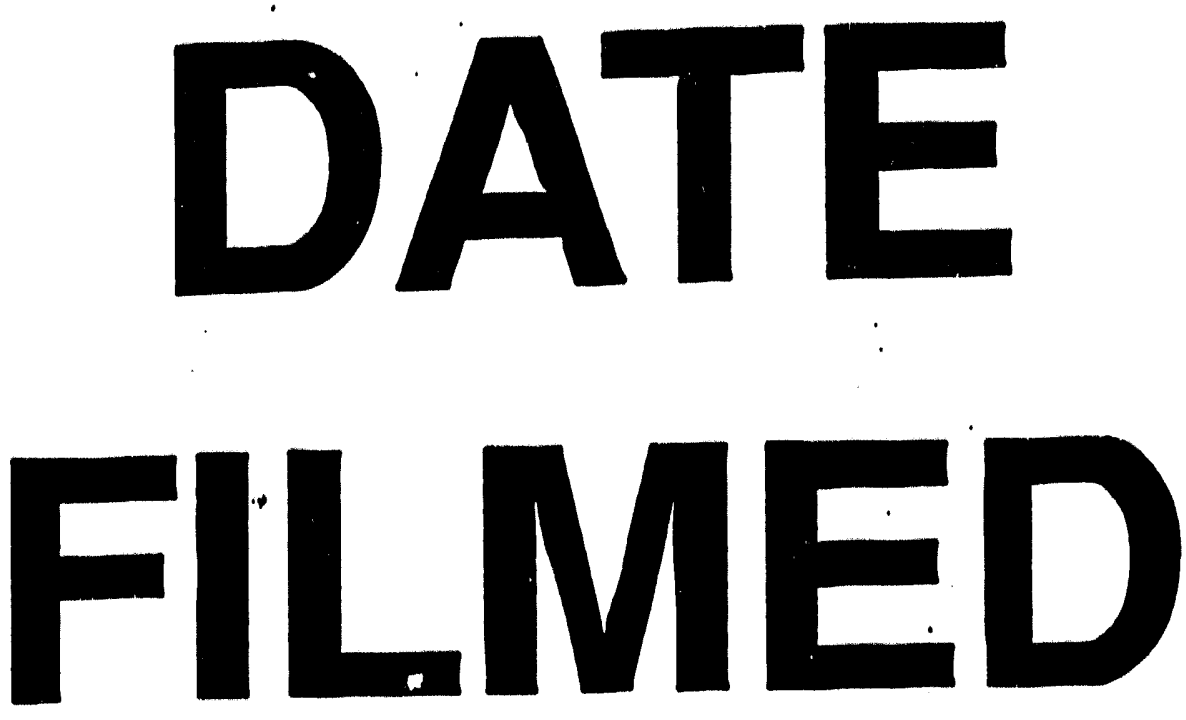

$1 / 5 / 94$
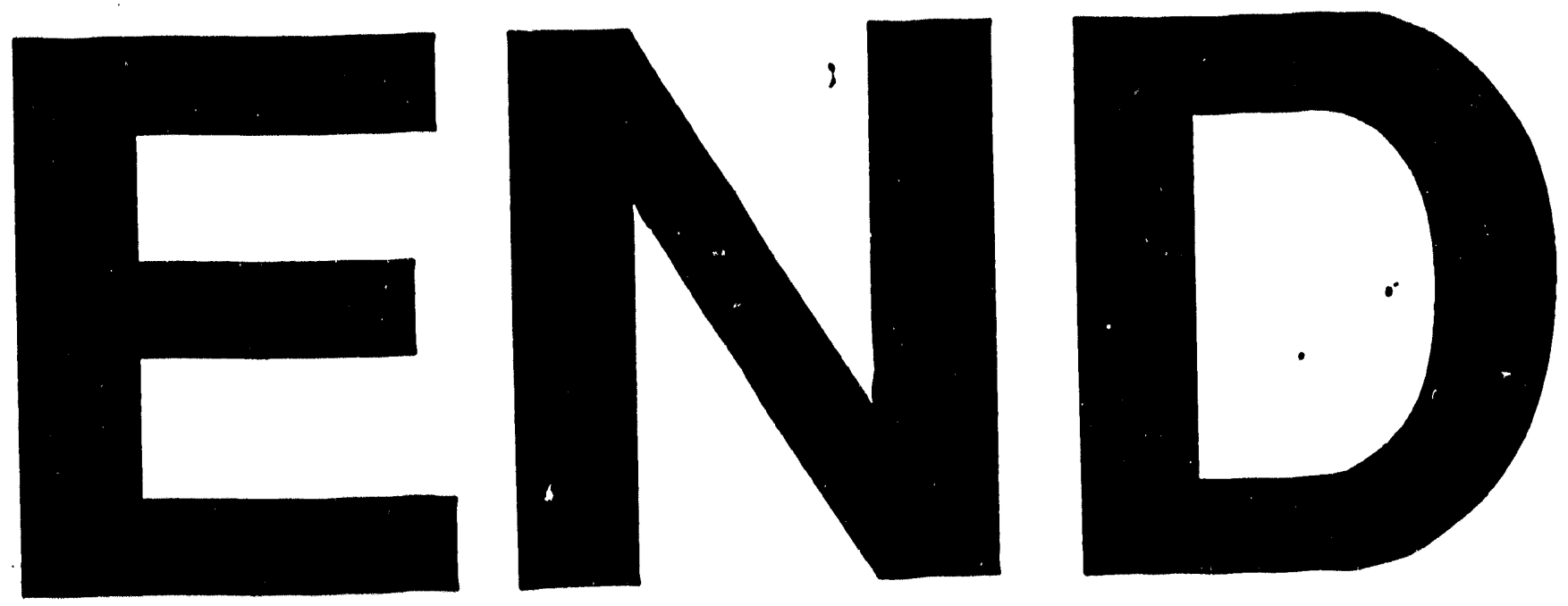

$-$ 